\title{
Utilisation et gestion des pesticides en cultures maraîchères : cas de la zone de Nkolo dans la province du Kongo Central, République démocratique du Congo
}

\author{
Tony M. Muliele ${ }^{1 *}$, Constantine M. Manzenza ${ }^{1}$, Léon W. Ekuke ${ }^{1}$, Cécile P. Diaka², Dieudonné M. \\ Ndikubwayo ${ }^{3}$, Olivier M. Kapalay ${ }^{1} \&$ Aimé N. Mundele ${ }^{4}$ \\ 1 Institut National pour l'Étude et la Recherche Agronomiques (INERA). B.P. 2037, Kinshasa I, RD Congo. \\ 2 World Vision, Kasangulu Integrated Programme. P.O. Box 942, Kinshasa / Gombe, DR Congo. \\ ${ }^{3}$ Université de Liège (ULg), Gembloux Agro-Biotech., Laboratoire de Phytopharmacie, Passage des Déportés 2, B-5030, \\ Gembloux, Belgique. \\ ${ }^{4}$ Ferme École MIKALO, Kinshasa, RD Congo. \\ *Auteur correspondant : tonymuliele@yahoo.fr, (+243) 0853158822.
}

Original submitted in on 27 $7^{\text {th }}$ September 2017. Published online at www.m.elewa.org on $30^{\text {th }}$ November 2017 https://dx.doi.org/10.4314/jab.v119i1.11

\section{RESUME}

Objectifs : L'objectif de cette étude est d'évaluer les connaissances et les pratiques des maraîchers de Nkolo et ses environs quant à l'utilisation des pesticides.

Méthodologie et Résultats : Une enquête a été réalisée auprès des 46 maraîchers. Le questionnaire a porté sur les pesticides utilisés, la dose appliquée, la préparation des solutions des pesticides, la fréquence d'application, la protection des maraîchers pendant l'usage des pesticides, la durée avant récolte (DAR), la gestion d'emballages des pesticides et les caractéristiques socio-professionnelles des maraîchers. Les résultats ont montrés que le maraîchage est généralement pratiqué par les hommes ( $93 \%$ contre $7 \%$ de femmes), et concerne principalement la culture des légumes fruits (tomate, aubergine et poivron). Les pesticides sont systématiquement appliqués, notamment les fongicides et les insecticides, à titre préventif et fréquemment à intervalle de 7 jours (saison pluvieuse) et 14 jours (saison sèche). Un à neuf pesticides différents peuvent être utilisés par cycle de culture, et sont généralement mélangés et appliqués en une fois à l'aide d'un pulvérisateur. Le dosage des pesticides et la DAR varient largement suivant les maraîchers. La majorité de maraîchers n'a pas suivi une formation sur les pesticides $(83 \%)$, ne se protège pas adéquatement pendant l'usage des pesticides (72\%) et abandonne les emballages des pesticides au champ (46\%).

Conclusion et applications des résultats : Les maraîchers de Nkolo et ses environs n'ont généralement pas une bonne connaissance des pesticides et ne respectent pas les recommandations des fabricants. L'application systématique des pesticides sans tenue de protection appropriée les met en contact régulier avec les pesticides et les expose à l'intoxication aux pesticides. Le manque de maîtrise de dosage des pesticides peut accroître le risque de résistance des ravageurs et pathogènes aux pesticides. En vue de réduire le risque d'intoxication des maraîchers et consommateurs des légumes, et de la pollution de l'environnement, il est d'ores et déjà, urgent et important de promouvoir la formation des maraîchers de Nkolo pour une utilisation judicieuse des pesticides.

Mots clés : Pesticides, cultures maraîchères, pratiques culturales, enquête, Nkolo (RD Congo). 


\section{Pesticides use and management in the vegetable crops at Nkolo in Kongo Central Province in the western DR Congo ABSTRACT}

Objectives: Pesticides are systematically applied in vegetable crops at Nkolo (in Kongo Central province in the western DR Congo) in order to provide crop protection and improve the yield. This study aimed at assessing the knowledges and practices of gardeners in relation to of pesticides use.

Methodology and Results : Forty-six gardeners were interviewed. The questionnaire focused on the pesticides types, solution procedures, application rate and frequency, gardener protective equipment, and the pre-harvest intervals. Socio-professional traits of gardeners were also recorded. Majority of gardeners was male $(93 \%$ vs $7 \%$ of women). Pesticides, especially fungicides and insecticides are systematically applied, based on preventive application and generally in 7 (dry season) and 14 (rain season) days of intervals. Depending on the gardener, 1 to 9 pesticides are used per crop cycle. All the pesticides are generally mixed and applied together on the crops using a manual sprayer. Application rate and pre-harvest intervals varied with gardeners. Most of them do not have been trained on pesticide use (83\%), do not use protective equipment $(72 \%)$ and abandon pesticide containers in the field $(46 \%)$.

Conclusion and application of results: Gardeners in Nkolo and surroundings have poor knowledges on pesticides use and do not use it properly. Systematically application of pesticides without proper protective equipment result in regular contact of gardener with pesticides and exposes them to pesticide poisoning. Furthermore, improper pesticides use should increase the risk of pest resistance in the long term use. In order to mitigate the risk of poisoning for gardeners and consumers, and environmental pollution in Nkolo and surroundings, there is an urgent need to promote proper use of pesticides.

Keywords: Pesticides, vegetables crops, agricultural practices, survey, Nkolo (DR Congo).

\section{INTRODUCTION}

Dans plusieurs pays africains (par exemple le Sénégal, le Benin, le Togo, la RD Congo), la population urbaine (capitales et villes secondaires) connaît une forte augmentation due à un taux de natalité élevé et à l'exode rural toujours croissant (Kanda et al., 2013 ; Boroto, 2014). Pour Kinshasa, capitale de la RD Congo, la population urbaine est passée de 300.000 en 1960 à plus de 10.000. 000 habitants en 2010 (Boroto, 2014). Cette forte augmentation de la population urbaine entraine plusieurs défis, entre autres la sécurité alimentaire (l'approvisionnement de ces villes en denrées alimentaires), la création d'emploi et la génération de revenus (Kanda et al., 2013; Boroto, 2014; Mondedji et al., 2015 ; Muliele et al., 2017). En vue de relever ces défis, les familles pauvres des villes recourent à l'agriculture urbaine et périurbaine, notamment le maraîchage (Mawussi et al., 2014 ; Muliele et al., 2017). A Kinshasa et ses banlieues, le maraîchage urbain et péri-urbain concerne essentiellement les légumes feuilles (par exemple, l'amarante, la morelle, les épinards, l'oseille) (Muzingu, 2009 ; Muliele et al., 2017). Dans les sites plus éloignés de Kinshasa (> $100 \mathrm{~km}$ ), des pôles d'approvisionnement des villes en produits maraîchers se sont développés. Les principaux pôles d'approvisionnement de la ville de Kinshasa en produits maraîchers situés dans la province du Kongo Central sont: Kisantu, Mbanza-Ngungu, Nkolo, Kimpese et leurs environs. Ces pôles maraîchers exploitent généralement les légumes fruits (la tomate, le poivron, l'aubergine, le gombo, la pastèque), tubercules/bulbe (la carotte, l'oignon) et quelques légumes feuilles exotiques (ciboule, poireau). En effet, les légumes feuilles locaux (amarante, oseille, morelle) perdent rapidement leur valeur marchande lorsqu'ils sont transportés dans des conditions inappropriées (fanaison après exposition aux rayons salaires ou à une température élevée) et sont généralement économiquement moins rentables lorsque transportés sur des longues distances, à coût de transport très élevé. Contrairement aux pratiques courantes des maraîchers producteurs des légumes feuilles locaux qui utilisent rarement ou pas de pesticides chimiques de synthèse, l'usage de ces derniers est la règle 
pour les maraîchers producteurs des légumes fruits, tubercules/bulbes et feuilles exotiques dont les semences sont importées des pays tempérées. A Nkolo et ses environs en province du Kongo Central en RD Congo, la forte demande de pesticides chimiques de synthèse par les maraîchers a conduit à la création des officines de vente des pesticides dont les tenanciers n'ont généralement pas suivi une formation experte sur l'utilisation des pesticides. Par ailleurs, si l'utilisation des pesticides est indispensable pour contrôler les ravageurs en vue d'optimiser les rendements des cultures maraîchères (rendement supérieur par unité de surface et produit de bonne qualité c.-à-d. légumes frais propres sans taches ou perforations visibles causées par des pathogènes).II est important de remarquer les pesticides chimiques sont toxiques et leur usage ne saurait être admis ou encourager qu'à condition de maîtriser parfaitement les modes d'usage ainsi que les risques pour la santé humaine et les milieux naturels susceptibles d'être affectés (Deviller et al., 2005 ; Sougnabe et al., 2010 ; Kanda et al., 2013). Les enquêtes de l'OMS ont révélé que les pays africains importent moins de $10 \%$ des pesticides utilisés dans le monde, pourtant ils totalisent la moitié des empoisonnements accidentels et plus de $75 \%$ des cas mortels (Tachin, 2011). Près de 750

\section{MATERIEL ET METHODES}

Une enquête a été conduite auprès des maraîchers de Nkolo et ses environs. Nkolo $\left(5,62^{\circ} \mathrm{S}, 14,85^{\circ} \mathrm{E}, 425 \mathrm{~m}\right.$ d'altitude, Figure 1) est une cité du territoire de MbanzaNgungu en province du Kongo Central, RD Congo. II appartient au climat de type Aw4 (climat tropical avec 4 mois de sèche) suivant la classification de Köppen. La distribution annuelle des pluies est bimodale ('saison A' et 'saison B') avec une moyenne annuelle variable entre 1400 et $1600 \mathrm{~mm}$ (Mfuti et al., 2016). L'enquête a couvert la période allant du 12 au 31 janvier 2017. Au total 46 maraîchers, tous utilisateurs des pesticides, ont été enquêtés sur l'usage des pesticides en cultures maraîchères. Le questionnaire était adressé aux propriétaires des exploitations maraîchères et a porté sur l'exploitation, l'usage et les principales pratiques d'application des pesticides. II s'agit notamment des pesticides utilisés, la dose appliquée, le mode de préparation des solutions des pesticides et leurs applications, la fréquence d'application, la protection des
000 personnes contractent chaque année une maladie chronique telle que le cancer suite à une exposition à des pesticides, des atteintes nerveuses, la stérilité et des malformations, etc. En outre, bien que les pays en développement n'emploient que $20 \%$ de l'ensemble des produits chimiques utilisés dans l'agriculture à l'échelle mondiale, ils totalisent cependant plus de $99 \%$ des décès dans le monde suite aux empoisonnements par les pesticides (Tachin, 2011). D'où la nécessité de promouvoir une utilisation judicieuse des pesticides pour combattre efficacement les ennemis des cultures tout en prévenantl'intoxication du producteur (agriculteur) et du consommateur, éviter le gaspillage des pesticides et la pollution de l'environnement. Pour y arriver, il s'avère important, avant tout, d'évaluer les connaissances et les pratiques actuelles des maraîchers sur l'usage des pesticides afin de définir les axes prioritaires susceptibles de promouvoir une utilisation appropriée des pesticides. Une telle étude ne semble pas, à notre connaissance, avoir été jusque-là faite dans la zone de Nkolo en RD Congo. L'objectif de cette étude est donc d'évaluer les connaissances et les pratiques des maraîchers de Nkolo et ses environs quant à l'utilisation des pesticides.

maraîchers pendant l'usage des pesticides, la durée avant récolte (DAR) appliquée, la gestion d'emballages des pesticides. Les caractéristiques socioprofessionnelles des maraîchers ont été également évaluées. Pour évaluer la dose des pesticides appliquée, le volume des pesticides liquides a été déterminé à l'aide d'un pied gradué ou d'une seringue et la masse des pesticides en poudre a été pesée sur balance de précision $( \pm 0,05 \mathrm{~g})$. En effet, dans la pratique les maraîchers utilisent les contenants de mesure fournis par le fabricant ou leurs propres récipients de fortune (boite de tomate vide, paquet à allumettes vide, cuillère, bouchon de bière, bouchon à bidon). Les données de l'enquête ont été encodées et dépouillées sous Excel, les valeurs extrêmes qui affectent sensiblement la tendance des paramètres centraux (moyenne, médiane) ont été éliminées. Le logiciel SPSS (version 17) a été utilisé pour le calcul de statistique descriptive (moyenne, médiane, 
fréquence et pourcentage) et du test de comparaison des moyennes (Test de Wilcoxon, $P=0,05$ ).

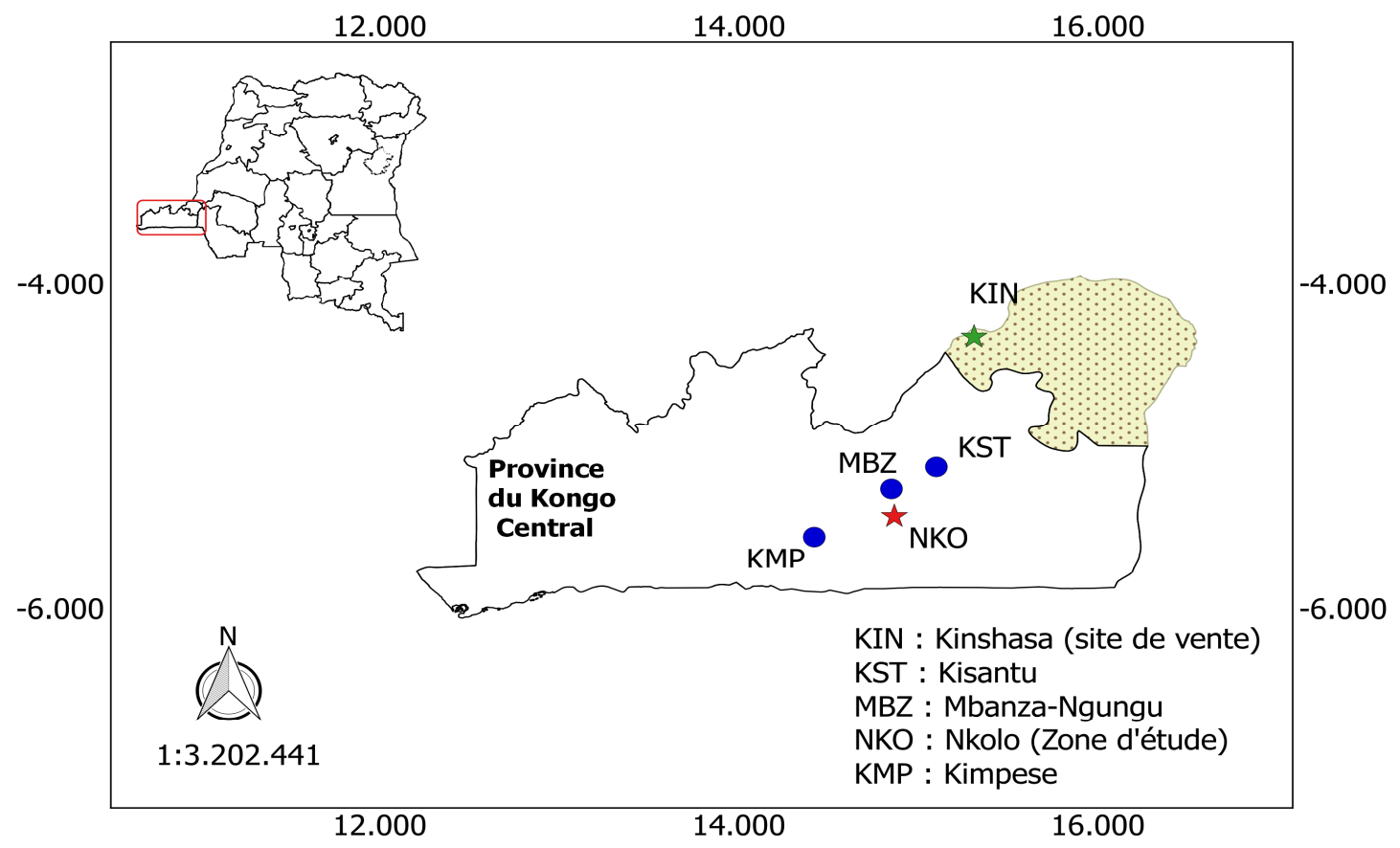

Figure 1 : Localisation de la zone d'étude et de quelques pôles d'approvisionnement de la ville de Kinshasa en produits maraîchers situés dans la province du Kongo Central.

\section{RESULTATS}

Caractéristiques socio-professionnelles des maraîchers : Le tableau 1 montre que le maraîchage est principalement pratiqué par les hommes, et les personnes âgées de 20 à 49 ans. Les individus de moins de 20 ans et de plus de 50 ans représentent environ $18 \%$ des maraîchers enquêtés. En ce qui concerne le niveau d'études, la plupart des maraîchers (environ 70\%) avait fait les études secondaires, comparée à ceux ayant seulement le niveau primaire ( $4 \%$ ) ou universitaire $(26 \%)$. Le maraîchage intéresse à la fois les personnes qui ont suivi la formation agricole et non agricole, ce dernier groupe représente plus de la moitié de maraîchers enquêtés. II importe de noter que $43 \%$ d'enquêtés pratiquaient le maraîchage comme une activité secondaire.

Tableau 1: Caractéristiques socio-professionnelles des maraîchers enquêtés

\begin{tabular}{l|l|c|c}
\hline Paramètres & & Effectif $\mathbf{(} \mathbf{= 4 6})$ & $\%$ \\
\hline Genre & Homme & 43 & 93,47 \\
\hline & Femme & 3 & 6,52 \\
\hline Age (ans) & $<20$ & 5 & 10,86 \\
\hline & $20-29$ & 13 & 28,26 \\
\hline & $30-39$ & 16 & 34,78 \\
\hline & $40-49$ & 9 & 19,56 \\
\hline Niveau d'études & $\geq 50$ & 3 & 6,52 \\
\hline & Primaire & 2 & 4,34 \\
\hline & Secondaire & 32 & 69,56 \\
\hline Formation agricole & Universitaire & 12 & 26,08 \\
\hline & Oui & 19 & 41,30 \\
\hline & Non & 27 & 58,69 \\
\hline
\end{tabular}


Principales cultures maraîchères exploitées par les maraîchers de Nkolo: Les principales cultures maraîchères cultivées sont la tomate $(96 \%$ des maraîchers), l'aubergine (33\% des maraîchers) et le poivron (24\% des maraîchers). La culture de chou pommé et de persil attire très peu de maraîchers (Tableau 2). Quarante-quatre maraîchers sur 46 enquêtés justifient leur préférence des cultures maraîchères comparativement aux cultures vivrières (manioc, arachide, maïs, etc.) par le fait que les cultures maraîchères ont un cycle court et sont faciles à pratiquer , et l'investissement en cultures maraîchères est rentable à court terme. Mises à part ces deux raisons majeures, un des maraîchers enquêtés a également évoqué la grande valeur marchande des cultures maraîchères, notamment les légumes fruits dont la tomate, le poivron.

Tableau 2 : Principales cultures maraîchères cultivées, et les principales raisons de leurs choix par les maraichers de Nkolo et ses environs..

\begin{tabular}{l|c|c}
\hline & Effectif $\mathbf{( n = 4 6 )}$ & $\%$ \\
\hline Cultures maraîchères & 44 & 95,65 \\
Tomate (Lycopersicon esculantum L.) & 15 & 32,60 \\
Aubergine (Solanum melongena L.) & 11 & 23,91 \\
Poivron (Capsicum annum) & 2 & 4,34 \\
Chou pommé ou chou cabus (Brassica oleracea) & 1 & 2,17 \\
Persil (Petroselinum crispum) & & \\
Raisons de choix des cultures maraîchères & 44 & 95,65 \\
Cultures à cycle court et facile à pratiquer & 43 & 93,47 \\
Investissement rentabilisable à court terme & 1 & 2,17 \\
Cultures à très grande valeur marchande par unité de surface & & \\
\hline
\end{tabular}

\section{Usage des pesticides}

Principaux pesticides utilisés par les maraîchers de Nkolo et ses environs: Sur base de noms commerciaux, 27 pesticides chimiques de synthèse ont été enregistrés dont 19 étaient effectivement appliqués ou en cours d'application (Tableau 3). Ces pesticides étaient essentiellement des fongicides et des insecticides, et dans une moindre mesure (soit 11\%), des insecticidesacaricides. Ils sont tous recommandés pour les cultures maraîchères et fruitières, et sont homologués en RD Congo. Les matières actives les plus fréquentes dans les pesticides utilisés sont l'abamectine, le lambdacyhalothrine et le mancozèbe. Un seul des maraîchers enquêtés, utilisait, en plus des pesticides chimiques de synthèse, un produit local, à composition chimique inconnue, préparé à base d'un mélange de feuilles de papayer et de tabac, du pétrole et du piment piquant. Pour chaque maraîcher enquêté, les pesticides utilisés ont été classés en fonction de leurs matières actives. Ceci a permis de déceler qu'un des maraîchers enquêtés utilisait à la fois deux pesticides à base d'abamectine (Acarius et Abastar) tandis que 3 autres maraîchers (soit $7 \%$ d'enquêtés) ont appliqué à la fois Gogga et Ivory 80 , à base de mancozèbe. Les sites d'approvisionnement en pesticides sont : le site local de Nkolo, Mbanza-Ngungu, Kinshasa (principal lieu de vente des produits maraîchers) et Kimpese (Figure 1) qui couvre, respectivement $72 \%, 13 \%, 13 \%$ et $1,6 \%$ des besoins en pesticides.

Dosage appliqué des pesticides : Des 19 pesticides cidessous listés (Tableau 3), 6 sont couramment utilisés par les maraîchers de Nkolo et ses environs. II s'agit notamment de Abastar, Banko Plus, Cyperméthrine, Ivory 80 , Pacha et Sycomyl. L'analyse de dosage appliqué des pesticides sera limitée uniquement à ces 6 pesticides. 
Muliele et al., J. Appl. Biosci. 2017 Utilisation et gestion des pesticides en cultures maraîchères : cas de la zone de Nkolo dans la province du Kongo Central, République démocratique du Congo

Tableau 3 : Liste des pesticides appliqués ou en cours d'application pendant l'enquête.

\begin{tabular}{|c|c|c|c|c|c|c|c|c|}
\hline $\begin{array}{l}\text { Nom } \\
\text { commercial }\end{array}$ & $\begin{array}{l}\text { Catégories de } \\
\text { pesticides }\end{array}$ & Familles & Matière active & \begin{tabular}{|l|} 
Classe \\
FAO/OMS
\end{tabular} & Dose (fabricant) & $\begin{array}{l}\text { Intervalle } \\
\text { d'application } \\
\text { (jrs) }\end{array}$ & DAR (jrs) & $\begin{array}{l}\text { Fréquence } \\
(\%)\end{array}$ \\
\hline Abastar 1,8 EC & $\begin{array}{l}\text { Insecticide + } \\
\text { Acaricide }\end{array}$ & Avermectines & Abamectine 1,8 g/L & - & $250 \mathrm{ml} / \mathrm{ha}$ & & 3 & 8,59 \\
\hline Acaricide $18 \mathrm{EC}$ & \begin{tabular}{|l|} 
Insecticide \\
\end{tabular} & Avermectines & Abamectine $1,8 \%$ & - & 20 à $35 \mathrm{ml} / 10 \mathrm{~L}$ & & - & 0,61 \\
\hline Acarius $18 \mathrm{EC}$ & $\begin{array}{l}\text { Insecticide + } \\
\text { Acaricide }\end{array}$ & Avermectines & Abamectine $18 \mathrm{~g} / \mathrm{L}$ & - & $\begin{array}{l}25 \text { à } 35 \mathrm{ml} / 10 \mathrm{~L} \\
(0,5 \text { à1 L/ha) }\end{array}$ & & 3 & 2,45 \\
\hline Banko Plus & \begin{tabular}{|l} 
Fongicide \\
\end{tabular} & $\begin{array}{l}\text { Chloronitrile+ } \\
\text { Benzimidazole }\end{array}$ & $\begin{array}{l}\text { Chlorothalonil } 550 \mathrm{~g} / \mathrm{L}+ \\
\text { Carbendazim 100g/L }\end{array}$ & $\mathrm{U}$ & $\begin{array}{l}50-75 \mathrm{ml} / 15 \mathrm{~L} \\
\text { (2L/ha) }\end{array}$ & 7 à 14 & 3 & 18,40 \\
\hline Cuivre & Fongicide & $\begin{array}{l}\text { Substance } \\
\text { inorganique }\end{array}$ & $\mathrm{Cu}$ & II & & & - & 3,07 \\
\hline $\begin{array}{l}\text { Cyperméthrine } \\
50 \mathrm{EC}\end{array}$ & Insecticide & $\begin{array}{l}\text { Pyréthroïde } \\
\text { synthétique }\end{array}$ & Cypermethrin $50 \mathrm{~g} / \mathrm{L}$ & II & 24 à $40 \mathrm{ml} / 15 \mathrm{~L}$ & & 7 à 15 & 9,20 \\
\hline $\mathrm{Fe}$ & & $\begin{array}{l}\text { Substance } \\
\text { inorganique }\end{array}$ & $\mathrm{Fe}$ & II & & & - & 4,91 \\
\hline $\begin{array}{l}\text { Fongized Super } \\
75 \text { WP }\end{array}$ & Fongicide & $\begin{array}{l}\text { Dithiocarbamate et } \\
\text { composé } \\
\text { apparenté+ } \\
\text { Acylamine }\end{array}$ & $\begin{array}{l}\text { Mancozèbe } 25 \mathrm{~g} / \mathrm{kg}+ \\
\text { Metalaxyl } 50 \mathrm{~g} / \mathrm{kg}\end{array}$ & U & 25 à $50 \mathrm{~g} / 16 \mathrm{~L}$ & 7 à 14 & - & 0,61 \\
\hline Gogga 80 WP & Fongicide & $\begin{array}{l}\text { Dithiocarbamate et } \\
\text { composé } \\
\text { apparenté }\end{array}$ & Mancozèbe $800 \mathrm{~g} / \mathrm{kg}$ & U & 50 à $75 \mathrm{~g} / 15 \mathrm{~L}$ & 7 à 10 & - & 1,84 \\
\hline Ivory 80 WP & Fongicide & $\begin{array}{l}\text { Dithiocarbamate et } \\
\text { composé } \\
\text { apparenté }\end{array}$ & Mancozèbe $800 \mathrm{~g} / \mathrm{kg}$ & U & 60 à $85 \mathrm{~g} / 15 \mathrm{~L}$ & 7 à 10 & - & 23,93 \\
\hline
\end{tabular}


Muliele et al., J. Appl. Biosci. 2017 Utilisation et gestion des pesticides en cultures maraîchères : cas de la zone de Nkolo dans la province du Kongo Central, République démocratique du Congo

\begin{tabular}{|c|c|c|c|c|c|c|c|c|}
\hline $\begin{array}{l}\text { Lang Karate } 050 \\
\text { EC }\end{array}$ & Insecticide & $\begin{array}{l}\text { Carbamate+ } \\
\text { Pyréthroïde } \\
\text { synthétique }\end{array}$ & $\begin{array}{l}\text { Pirimicarbe + Lambda- } \\
\text { cyhalothrine }\end{array}$ & II & $\begin{array}{l}150 \text { à } 250 \mathrm{ml} / 1 \mathrm{ha} \\
(5-15 \mathrm{ml} / 10 \mathrm{~L})\end{array}$ & 7 à 10 & - & 0,61 \\
\hline Manebe 800 WP & Fongicide & Dithiocarbamate & Manebe $800 \mathrm{~g} / \mathrm{kg}$ & $U$ & $1 \mathrm{~kg} / \mathrm{ha}$ & & - & 0,61 \\
\hline $\begin{array}{l}\text { Methoomethyl } \\
500 \text { WP }\end{array}$ & Fongicide & $\begin{array}{l}\text { Benzimidazole+ } \\
\text { Substance } \\
\text { inorganique }\end{array}$ & $\begin{array}{l}\text { Thiophanate de methyl } \\
(150 \mathrm{~g} / \mathrm{kg})+\text { oxychlorure } \\
\text { de soufre }(200 \mathrm{~g} / \mathrm{kg})+ \\
\text { soufre }(150 \mathrm{~g} / \mathrm{kg})\end{array}$ & $\begin{array}{l}\text { U } \\
\\
\text { III }\end{array}$ & $50 \mathrm{~g} / 16 \mathrm{~L}$ & & - & 0,61 \\
\hline Pacha 25 EC & Insecticide & $\begin{array}{l}\text { Pyréthroïde } \\
\text { synthétique + } \\
\text { Néonicotinoïdes }\end{array}$ & $\begin{array}{l}\text { Lambda-cyhalothrine } \\
15 \mathrm{~g} / \mathrm{L}+\text { Acetamipride } \\
10 \mathrm{~g} / \mathrm{L}\end{array}$ & II & $35 \mathrm{ml} / 10 \mathrm{~L}$ & & 7 & 4,91 \\
\hline Pesticide local & NA & NA & $\begin{array}{l}\text { Feuilles de papayer et } \\
\text { de tabac, pétrole, piment } \\
\text { piquant }\end{array}$ & - & NA & NA & NA & NA \\
\hline $\begin{array}{l}\text { Ridomil Gold } \\
\text { Plus } 660 \text { WP }\end{array}$ & Fongicide & $\begin{array}{l}\text { Phenylamide+Su } \\
\text { bstance } \\
\text { inorganique }\end{array}$ & $\begin{array}{l}\text { Méfénoxam } 60 \mathrm{~g}+ \\
\text { Cuivre } 600 \mathrm{~g}\end{array}$ & $\|$ & $50 \mathrm{~g} / 15 \mathrm{~L}$ & 21 & 30 & 0,61 \\
\hline Super Kill 50 EC & Insecticide & $\begin{array}{l}\text { Pyréthroïde } \\
\text { synthétique }\end{array}$ & Cypermethrin $50 \mathrm{~g} / \mathrm{L}$ & II & $\begin{array}{l}\text { selon le degré } \\
\text { d'infestation }\end{array}$ & & - & 0,61 \\
\hline $\begin{array}{l}\text { Talaxyl Super } 35 \\
\text { WP }\end{array}$ & Fongicide & Acylamine & Métalaxyl $35 \%$ & II & $15 \mathrm{~g} / 16 \mathrm{~L}$ & 30 à 40 & 10 & 0,61 \\
\hline Sycomyl 35 WP & Fongicide & Acylamine & Métalaxyl $35 \%$ & II & 20 à $40 \mathrm{~g} / 100 \mathrm{~L}$ & & 7 à 14 & 14,72 \\
\hline Zalang $50 \mathrm{EC}$ & Insecticide & $\begin{array}{l}\text { Pyréthroïde } \\
\text { synthétique }\end{array}$ & $\begin{array}{l}\text { Lambda-cyhalothrine } 50 \\
\mathrm{~g} / \mathrm{L}\end{array}$ & II & $\begin{array}{l}10 \mathrm{ml} / 10 \mathrm{~L} \\
(0,3 \mathrm{~L} / \mathrm{ha})\end{array}$ & 21 à 28 & 14 & 3,07 \\
\hline
\end{tabular}

Source : Notices des pesticides. EC : concentrés émulsifiables, WP : poudre mouillable. Classe I : extrêmement/hautement dangereux, Classe II : modérément dangereux, Classe III : légèrement dangereux, Classe $U$ : peu susceptible de présenter un danger pour l'homme dans les conditions normales d'utilisation. 
La figure 2 met en évidence une grande variabilité dans la pratique de dosage des pesticides par les maraîchers de Nkolo et ses environs. Pour un même pesticide et volume de solution (réservoir du pulvérisateur $=15 \mathrm{~L}$ ), la dose appliquée peut s'accroitre d'une fois et demie à environ quarante fois. Pour les maraîchers ayant utilisé Abastar, par exemple, la dose la plus faible et la plus élevée sont respectivement 2 et $80 \mathrm{ml} / 15 \mathrm{~L}$ d'eau (Figure 2.a). Si l'on se base sur la dose moyenne (ligne horizontale discontinue rouge sur les "box-plots", Figure 2) des pesticides appliquée par les maraîchers, la quantité des pesticides utilisée pour Banko Plus, Cyperméthrine, Pacha et Sycomyl, est généralement plus faible que celle recommandée par le fabricant (Tableau 3). Toutefois, pour la plupart des pesticides utilisés, la dose maximale appliquée est nettement supérieure à celle recommandée par le fabricant (Tableau 3 et Figure 2).
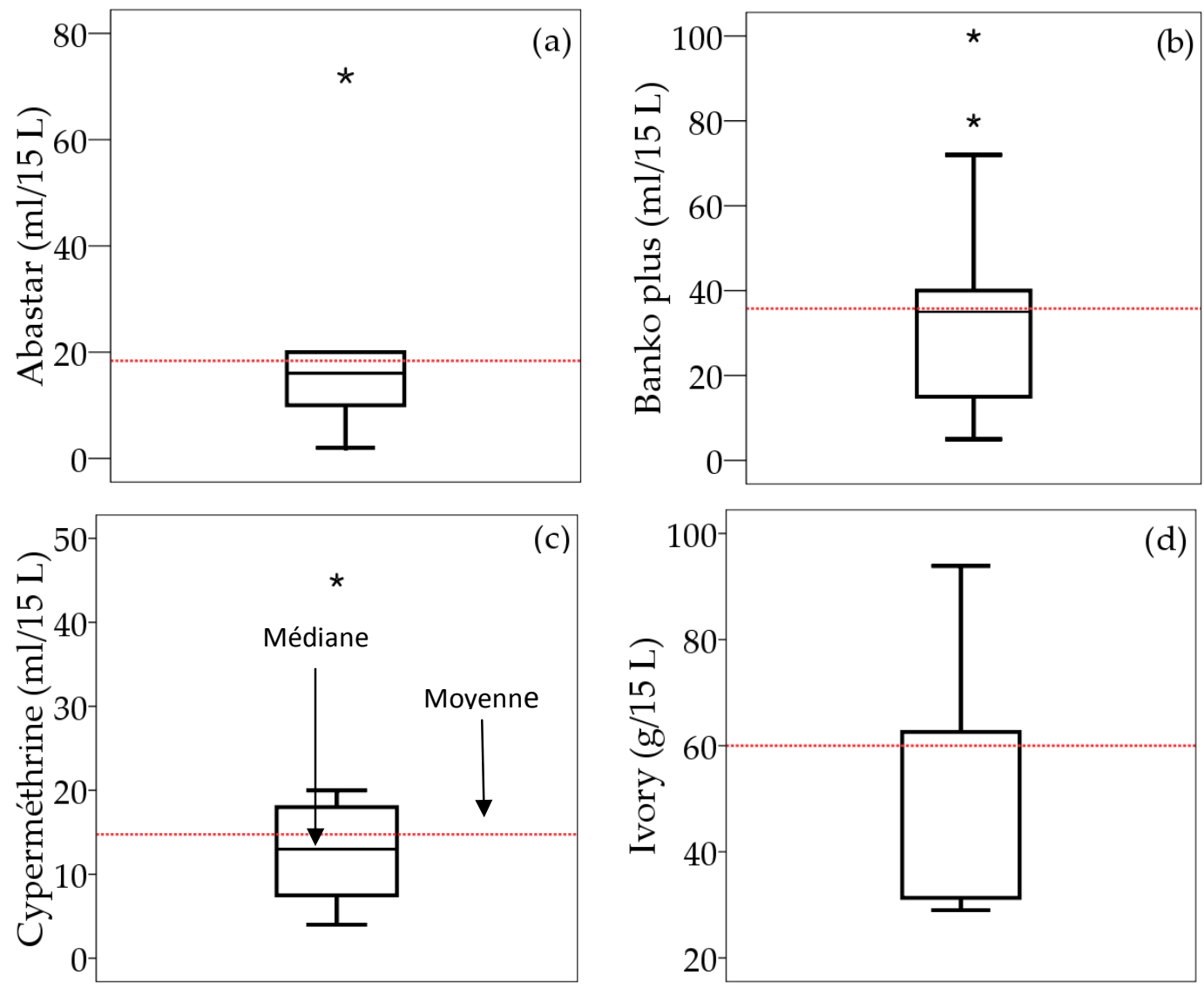

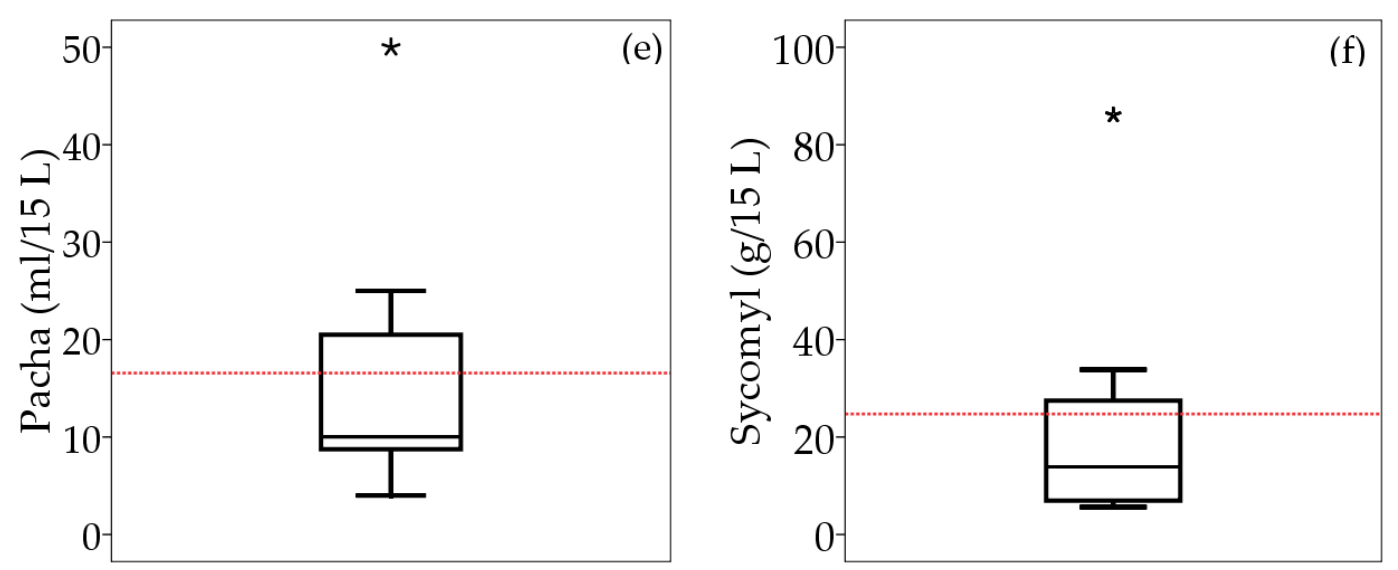

Figure 2 : Dosage des pesticides tel que appliqué par les maraîchers de Nkolo et ses environs. La ligne horizontale discontinue rouge sur les "box-plots" indique la dose moyenne appliquée par les maraîchers enquêtés.

Le tableau 4 présente les doses moyennes des pesticides appliqués par les maraîchers de Nkolo et ses environs suivant que les maraîchers ont suivi ou non une formation agricole. Ce tableau montre des valeurs supérieures (Banko Plus) ou légèrement supérieures (autres pesticides) pour les maraîchers n'ayant pas suivi une formation agricole. En dépit de cette tendance, la formation (agricole/non agricole) n'a pas affecté de manière significative le dosage des pesticides sur base du test non paramétrique de Wilcoxon, $P$-valeur $>0,05$ (Tableau 4.). Les valeurs très élevées d'écart-types illustrent la grande variabilité de doses des pesticides appliqués par les maraîchers de Nkolo et ses environs, initialement illustrée à la figure 2.

Tableau 4 : Comparaison de dosage des pesticides suivant le niveau de formation des maraîchers.

\begin{tabular}{l|c|c|c|c}
\hline Pesticides & Dose fabricant & Formation agricole & Sans formation agricole & P-valeur $^{*}$ \\
\hline Abastar (ml/ha) & 250 & $20,00 \pm 0,00[4]$ & $23,89 \pm 28,14[10]$ & $0,188^{\mathrm{ns}}$ \\
Banko Plus (ml/15L) & $50-75$ & $24,4 \pm 21,93[8]$ & $46,05 \pm 33,45[19]$ & $0,058^{\mathrm{ns}}$ \\
Cyperméthrine (ml/15L) & $24-40$ & $14,75 \pm 11,07[4]$ & $15,12 \pm 13,48[8]$ & $0,683^{\mathrm{ns}}$ \\
Ivory 80 (g/15L) & $60-85$ & $50,86 \pm 13,55[12]$ & $51,15 \pm 17,43[27]$ & $0,964^{\mathrm{ns}}$ \\
Pacha (ml/10L) & 35 & $10,00 \pm 0,00[2]$ & $18,75 \pm 16,93[8]$ & $0,857^{\mathrm{ns}}$ \\
Sycomyl (g/100L) & $20-40$ & $17,19 \pm 11,47[8]$ & $28,75 \pm 30,40[15]$ & $0,591^{\mathrm{ns}}$ \\
\hline
\end{tabular}

* Test non paramétrique de Wilcoxon. ns: non significatif au seuil de probabilité 0,05.

Valeurs = moyennes \pm écart-types. Les valeurs entre les crochets indiquent le $\mathrm{n}$ (nombre de maraîchers).

Préparation et application des pesticides : Le tableau 5 présente les pratiques de préparation des solutions des pesticides, protection pendant le traitement phytosanitaire et la gestion des emballages des pesticides telles que appliquées par les maraîchers de Nkolo et ses environs. 
Tableau 5 : Pratiques de préparation des solutions des pesticides, protection pendant la pulvérisation et gestion des emballages des pesticides par les maraîchers de Nkolo et ses environs.

\begin{tabular}{|c|c|c|c|}
\hline & Variantes & Effectif $(n=46)$ & $\%$ \\
\hline \multirow[t]{2}{*}{ Types de mélange/solution } & Un seul pesticide dans un pulvérisateur & 2 & 4,34 \\
\hline & Tous les pesticides à la fois dans un pulvérisateur & 44 & 95,65 \\
\hline \multirow[t]{3}{*}{ Vérification de la date d'expiration } & Oui & 42 & 91,30 \\
\hline & Non & 3 & 6,52 \\
\hline & Pas toujours & 1 & 2,17 \\
\hline \multirow{2}{*}{$\begin{array}{l}\text { Ayant déjà observé } \\
\text { des pesticides périmés }\end{array}$} & Oui & 12 & 26,08 \\
\hline & Non & 34 & 73,91 \\
\hline \multirow{10}{*}{$\begin{array}{l}\text { Gestion des emballages des } \\
\text { pesticides. }\end{array}$} & Abandonner au champ & 21 & 45,65 \\
\hline & Abandonner au champ ou restituer au fournisseur & 1 & 2,17 \\
\hline & Jeter dans un trou spécifique & 1 & 2,17 \\
\hline & $\begin{array}{l}\text { Jeter dans une toilette hors usage ou dans un cours } \\
\text { d'eau }\end{array}$ & 1 & 2,17 \\
\hline & Enfouir au champ & 3 & 6,25 \\
\hline & Incinérer & 10 & 21,74 \\
\hline & Incinérer ou enfouir au champ & 1 & 2,17 \\
\hline & Incinérer ou abandonner au champ & 1 & 2,17 \\
\hline & Jeter dans une toilette en usage & 5 & 10,87 \\
\hline & Jeter dans une poubelle domestique & 2 & 4,35 \\
\hline \multirow[t]{3}{*}{ Entretien du pulvérisateur } & Lavage au champ & 42 & 91,30 \\
\hline & Lavage dans un cours d'eau & 1 & 2,17 \\
\hline & Ne lave jamais le pulvérisateur & 3 & 6,52 \\
\hline \multirow[t]{2}{*}{$\begin{array}{l}\text { Port d'une tenue de protection } \\
\text { pendant la pulvérisation* }\end{array}$} & Oui & 13 & 28,26 \\
\hline & Non & 33 & 71,74 \\
\hline \multirow[t]{4}{*}{$\begin{array}{l}\text { Formation sur l'utilisation des } \\
\text { pesticides }\end{array}$} & Oui, à l'université & 5 & 10,87 \\
\hline & Oui, aux humanités agricoles & 2 & 4,35 \\
\hline & Oui, atelier ICART WV (INERA M'vuazi) & 1 & 2,17 \\
\hline & Non & 38 & 82,61 \\
\hline \multirow{2}{*}{$\begin{array}{l}\text { Connaissance de la composition } \\
\text { chimique des pesticides }\end{array}$} & Oui & 3 & 6,52 \\
\hline & Non & 43 & 93,47 \\
\hline
\end{tabular}

* tenue spéciale : port des bottes aux pieds, une combinaison/salopette ou chemise à manches longues/jacket imperméable + pantalon, cache-nez/pièce d'étoffe au nez, gants, casque/chapeau, lunette. Toutefois, la tenue spéciale ainsi décrite n'était pas toujours complètement enfilée par les maraîchers de ce groupe.

Les principales informations suivantes sont tirées du tableau 5 : i) les maraîchers de Nkolo et ses environs mélangent généralement 2 ou plusieurs pesticides et vérifient le plus souvent la date de péremption des produits phytosanitaires ; ii) ils abandonnent fréquemment les emballages des pesticides au champ (Photo 1), les incinèrent ou les jettent dans une toilette en usage ; iii) la majorité de ces maraîchers (72\%) n'ont pas le plus souvent de tenue appropriée pour se protéger pendant la manipulation des pesticides et, la plupart d'entre eux $(83 \%)$ n'a pas suivi une formation avancée sur l'utilisation des pesticides. Les pesticides sont ordinairement appliqués 1 à 2 fois (Figure 3.a) au germoir (environ 30 à 35 jours pour la tomate et le poivron). Pendant la saison 
sèche, les pesticides sont appliqués principalement à intervalle de 14 jours et dans une moindre mesure tous les 7 jours (Figure 3.b). Pendant la saison des pluies, par contre, l'intervalle d'application est plus court, soit généralement 7 jours (Figure 3.c). Quant au nombre de pesticides appliqués par cycle végétatif, il varie entre 1 et 9 pesticides suivant les maraîchers (Figure 3.d).
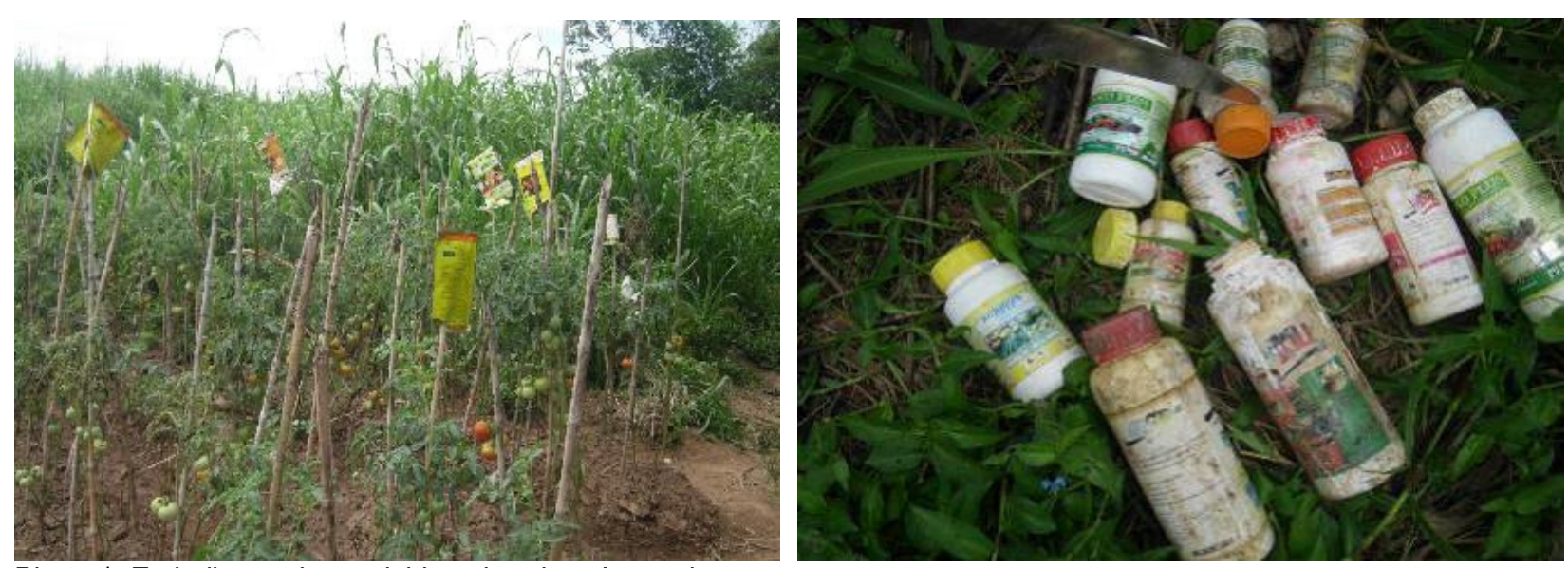

Photo 1. Emballages de pesticides abandonnés au champ.
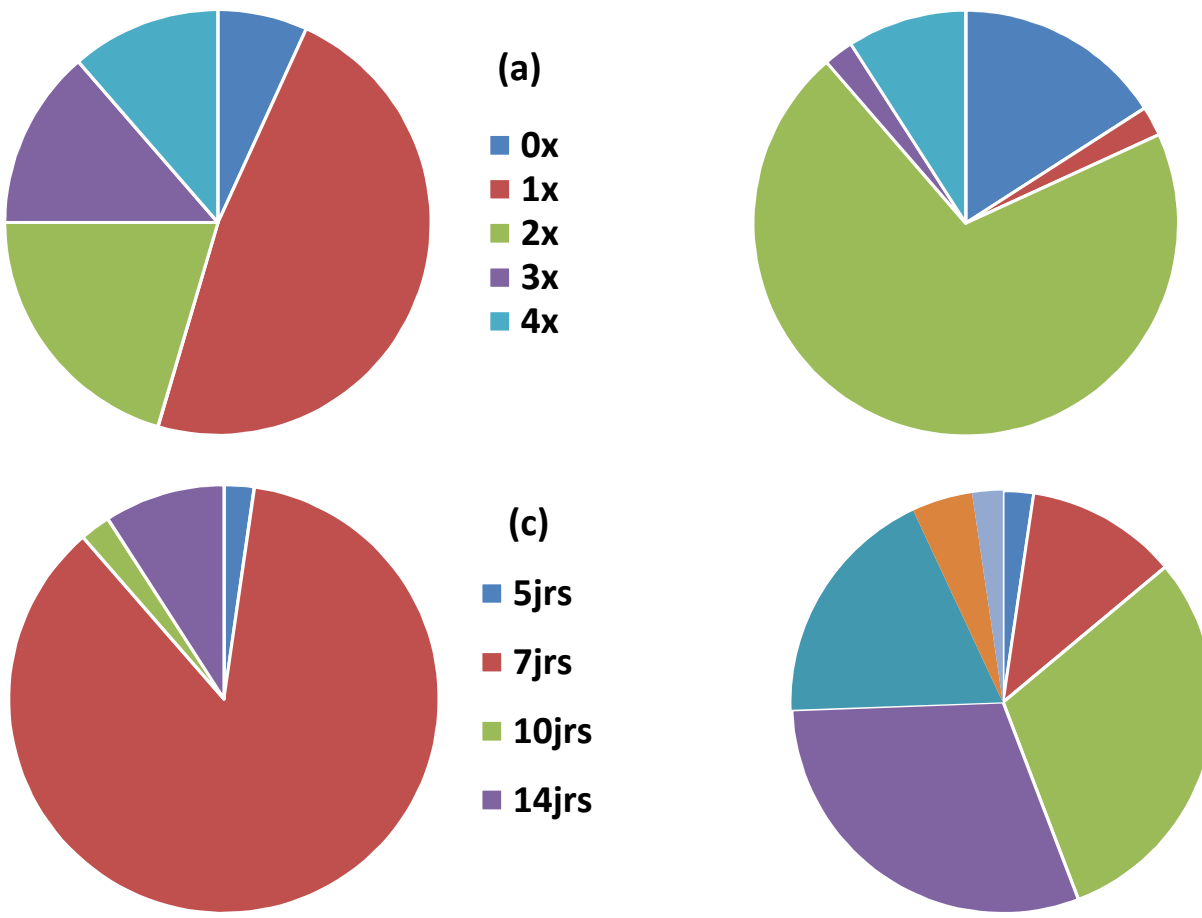

(b)

7jrs

11jrs

14jrs

-15jrs

$\square 21 \mathrm{jrs}$

Figure 3 : Fréquence d'application des pesticides au germoir (a), intervalle d'application des pesticides en saison sèche (b) et en saison des pluies (c) et nombre de pesticides appliqués/cycle de culture (d). 
Avantages et inconvénients de l'utilisation des pesticides: L'étude révèle que tous les maraîchers enquêtés (100\%) utilisent les pesticides. Ils justifient l'utilisation des pesticides en évoquant entre autre que : « la la culture des légumes tempérés (par exemple la tomate, le poivron) ne peut réussir sans usage des pesticides ». Les pesticides sont indispensables pour obtenir des plants sains, de beaux fruits (fruits de forme régulière et sans lésions) et de bons rendements. Par ailleurs, suivant leur expérience et/ou connaissance, les maraîchers ont également évoqué des effets néfastes liés à l'utilisation des pesticides (Tableau 6), principalement la brûlure de plants et la chute de fleurs en cas des doses excessives. Environ 20\% des maraîchers reconnaissent que l'usage des pesticides peut exposer à l'intoxication, alors que $7 \%$ des maraîchers soulignent, en plus, que les parasites et les ravageurs des plantes développent une résistance aux pesticides lorsque ceux-ci sont utilisés de manière inadéquate et continue. En dépit du risque d'intoxication liée à l'utilisation des pesticides susmentionné, l'étude montre que les mesures de précaution et/ou la tenue de protection sont inadéquates (Figure 4). En effet, cinq à dix-huit pourcent d'enquêtés seulement affirment que le port des bottes, des gants, du cache-nez, d'une chemise à manches longues et du pantalon est nécessaire pendant le traitement avec les pesticides. Cependant, ces mesures de précaution/tenue de protection sont rarement utilisées.

Tableau 6 : Principaux inconvénients liés à l'utilisation des pesticides évoqués par les maraîchers de Nkolo et ses environs

\begin{tabular}{l|l|l}
\hline Liste des inconvénients de l'utilisation des pesticides & Effectif $(\mathbf{n}=46)$ & $\%$ \\
\hline & 22 & 47,8 \\
Brûlure de plants et chute de fleurs en cas surdosage & 9 & 3 \\
& 19,5 \\
$\begin{array}{l}\text { Risque d'intoxication pour les utilisateurs } \\
\text { Utilisation inadéquate et continue des pesticides peut résulter en une résistance des } \\
\text { parasites aux produits utilisés }\end{array}$ & 3 & 7 \\
\hline
\end{tabular}

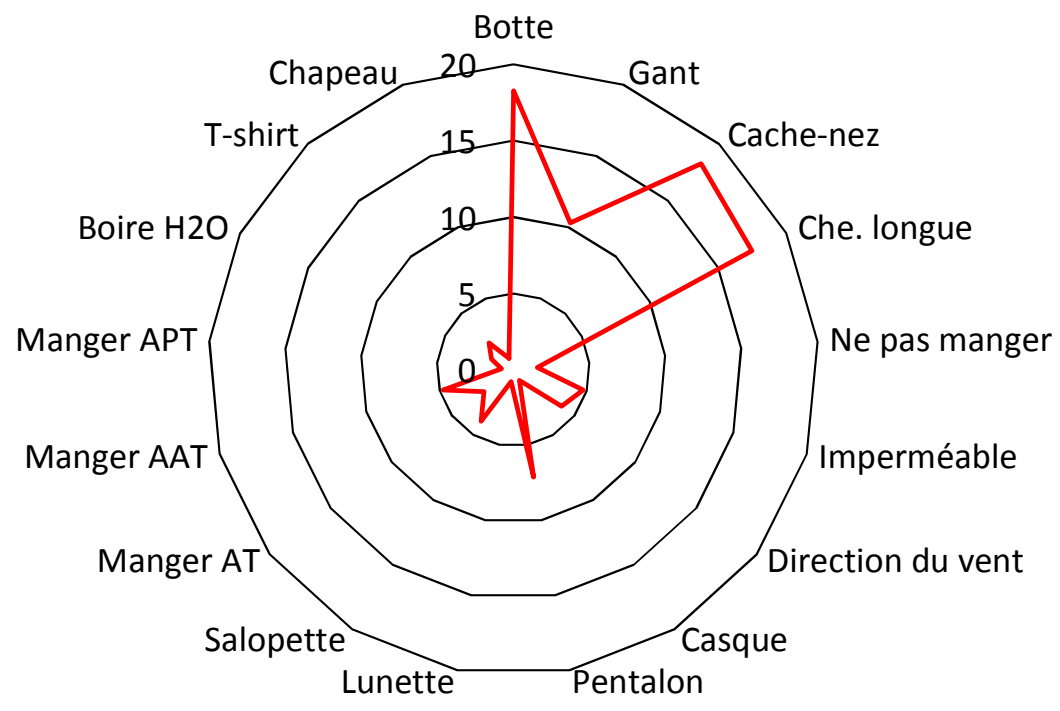

Figure 4 : Mesures de précaution contre les effets néfastes des pesticides et tenue de protection pendant la manipulation des pesticides. Les valeurs indiquent le \% des maraîchers. Manger APT : manger après le traitement, Manger AAT : manger avant et après le traitement, Manger AT : manger après traitement, Direction du vent : ne jamais traiter à contre-courant d'air, Chem. longue : port d'une chemise à manches longues.

Avis des maraîchers de Nkolo sur la durée avant récolte (DAR) et la consommation des produits maraîchers: La majorité des maraîchers enquêtés $(100 \%)$ reconnaissent la nécessité de respecter la durée 
avant récolte (DAR), c'est-à-dire le délai entre la dernière application d'un pesticide donné et la récolte d'une culture. Cependant cette durée est différemment appliquée comme illustrer à la figure 5.a pour la tomate, l'aubergine et le poivron. D'une manière générale, la récolte des légumes se fait 7 ou 14 jours après la dernière application des pesticides. Les plus longues DAR sont de l'ordre de 21 et 25 jours. Toutefois, ces dernières ne sont pas fréquemment appliquées $(<5 \%$ d'enquêtés). En ce qui concerne l'avis des maraîchers sur la consommation de leurs récoltes, chacun des maraîchers enquêtés a affirmé qu'il consomme, sans crainte de risque d'intoxication aux pesticides, les produits de ses propres récoltes (groupe AC) (Figure 5.b). Quant aux récoltes des autres maraîchers, 80\% seulement des maraîchers enquêtés (groupe Oui, PA) consomment sans condition ce que les autres maraîchers produisent. Les $20 \%$ d'enquêtés restants sont repartis en trois groupes égaux : les maraîchers qui consomment avec crainte de risque d'intoxication les récoltes des autres maraîchers (groupe Oui, DT), ceux qui ne consomment les récoltes des autres maraîchers que si le producteur est connu (groupe Oui, PC) et ceux qui ne consomment jamais les récoltes des autres maraîchers (groupe Non) (Figure 5.b).

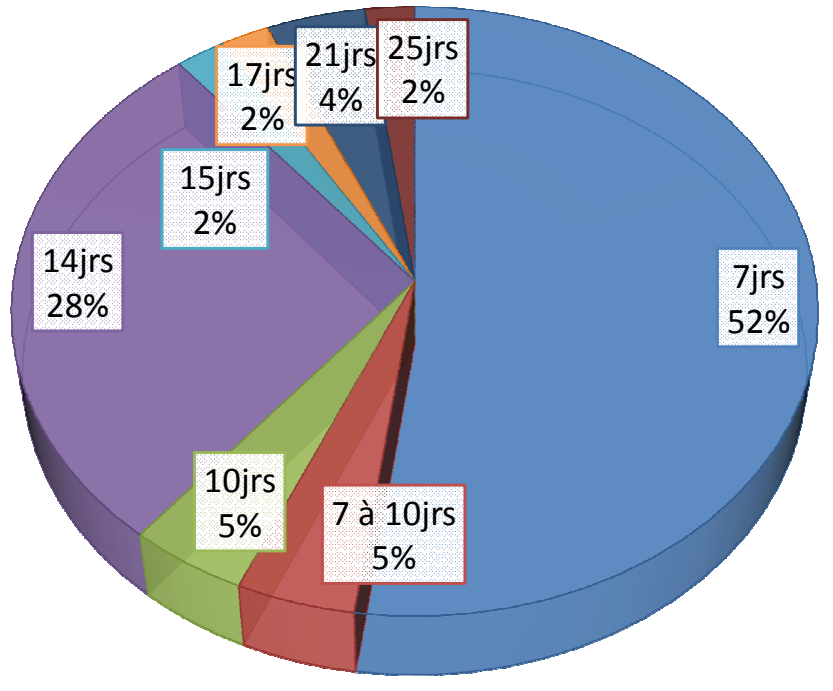

(a)

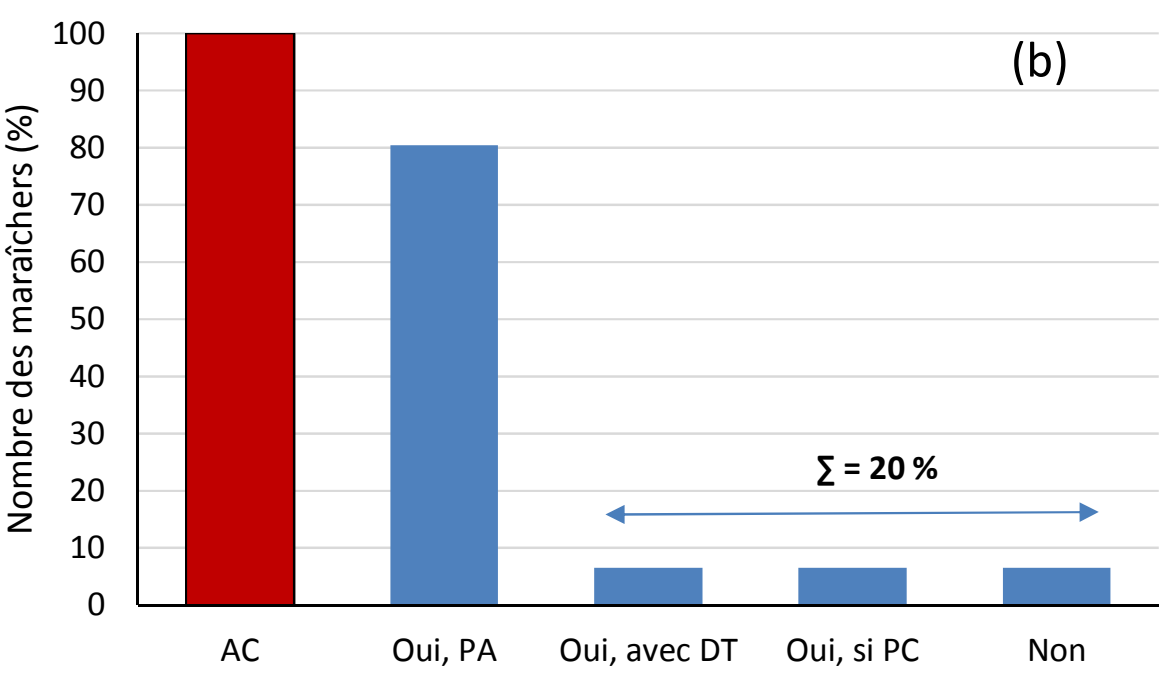

Consommation des produits maraîchers

Figure 5 : Durée avant récolte (DAR) et avis des maraîchers de Nkolo et ses environs sur la consommation des produits de leurs récoltes. 


\section{DISCUSSION}

Le maraîchage à Nkolo et ses environs est une activité principalement exercée par le genre masculin et concerne essentiellement les légumes fruits. Un faible pourcentage des femmes ( $8 \%$ - 28\%) est impliqué dans le maraîchage comme cela a été également rapporté par Mawussi et al. (2014) et Mondedji et al. (2015) au Togo. Pour cette étude, la faible implication des femmes ( $7 \%$, Tableau 1$)$ dans la production des légumes fruits (tomate, aubergine et poivron) pourrait être expliquée du fait que les femmes ne sont généralement pas habilitées à appliquer le traitement phytosanitaire dont exigent ces cultures. En effet, le traitement phytosanitaire est fastidieux (acquérir le produit, préparer la solution et l'appliquer au moyen d'un pulvérisateur), et compliqué pour les non-initiés qui constituent une part importante des femmes paysannes. Les quelques rares femmes impliquées dans la production des légumes fruits dans cette étude sont toutes lettrées $(B A C+3)$ et de Mvuazi (dans les environs de Nkolo), un centre de recherche de l'Institut National pour l'Étude et la Recherche Agronomiques (INERA). Leur habilité à utiliser les pesticides serait liée à l'initiation auprès de leurs époux et autres agents de l'INERA. Toutefois, contrairement aux légumes fruits, il est important de signaler que les femmes dans la zone d'étude sont activement impliquées dans la production des légumes locaux (amarante, morelle, oseille) qui ne nécessitent généralement pas de traitement phytosanitaire et qui sont le plus souvent semés à la volée sous cultures vivrières. Cette étude montre que le maraîchage est pratiqué par un panel de tranches d'âges (de moins de 20 à plus de 50 ans), majoritairement par les personnes ayant un niveau secondaire (BAC) et universitaire (BAC +3 ou 5 ) et sans formation agricole (>50 \% d'enquêtés) (Tableau 1). Pour la zone d'études, la culture des légumes fruits parait donc être une activité pourvoyeuse d'emploi et une source sure de revenu. Elle est également, à l'opposé des résultats de Wade (2003) et de Mawussi et al (2014), exercée majoritairement par les diplômés sans emploi et/ou sans salaire décent. En effet, $43 \%$ d'enquêtés exercent le maraîchage comme une activité secondaire. Dans la zone d'étude, les champs des légumes fruits sont nommés "projets", dans la mesure où menés à bien, au bout de 3 à 4 mois, les recettes des récoltes permettent aux maraîchers d'atteindre les objectifs qu'ils se sont assignés à l'installation de leurs champs maraîchers (par exemple, achat d'une moto, achat des meubles, payement des frais scolaires des enfants, etc.). Ceci démontre l'intérêt que les paysans accordent aux légumes fruits (tomate, aubergine et poivron) lorsque $95 \%$ de maraîchers enquêtés attestent que les cultures maraîchères ont un cycle court, sont faciles à pratiquer et constituent un investissement rentable à court terme (Tableau 2). En effet, comparées aux cultures vivrières, les cultures maraîchères peuvent être commercialisées directement après la récolte sans aucune transformation préalable (séchage, rouissage, décorticage). Certaines cultures vivrières ont un cycle végétatif de 18 mois, ce qui correspond à 4 à 5 cycles de quelques légumes fruits. Ces avantages qu'offrent les cultures maraîchères pourraient justifier un nombre croissant des maraîchers ces dernières années dans la zone d'études. Tous les maraîchers enquêtés $(100 \%)$ utilisent les pesticides. L'utilisation systématique des pesticides de synthèse pour optimiser les rendements en cultures maraîchères a été rapportée dans plusieurs autres pays africains comme le Bénin, la Côte d'Ivoire, le Ghana, le Sénégal et le Togo (Wade, 2003; Assogba-Komlan et al., 2007 ; Souganbe et al. 2010 ; Ahouangninou, 2013; Kanda et al., 2013 ; Mawussi et al., 2015 ; Mondedji et al., 2015). Ces auteurs ont également rapporté une utilisation inadéquate des pesticides, notamment en ce qui concerne le dosage, la préparation des solutions et l'application, la protection des maraîchers pendant le traitement, la gestion des emballages et la durée avant la récolte. Ces résultats corroborent avec ceux trouvés dans le cadre de cette étude. Les maraîchers de Nkolo et ses environs utilisent couramment les fongicides, les insecticides et dans une moindre mesure les insecticidesacaricides (Tableau 3) qu'ils appliquent au germoir et en pleine culture. L'application des pesticides est basée sur le traitement préventif («mieux vaut prévenir que guérir »), le plus souvent à intervalle de 7 (saison des pluies) à 14 jours (saison sèche). Bien que ce mode d'application des pesticides paraisse le plus efficace aux yeux des maraîchers pour contrôler les "pestes", il présente cependant quelques désavantages tels que le gaspillage des pesticides (donc de l'argent) en cas de faible incidence des "pestes", la toxicité des pesticides, l'accroissement de risque d'intoxication aux pesticides suite à l'exposition régulière dans la mesure où la majorité de maraîchers ne se protège pas adéquatement pendant le traitement phytosanitaire (Tableau 5 et Figure 4), I' augmentation du risque de pollution de l'environnement (eau, air, sol et autres êtres vivants). Quel que soit le produit utilisé, la figure 2 montre que les maraîchers n'ont pas une maîtrise des doses à appliquer et ils appliquent rarement la dose recommandée. Ceci paraît cependant paradoxal avec leur niveau d'études, $96 \%$ d'enquêtés ayant le niveau 
d'études secondaire ou universitaire. Le fait que la plupart des maraîchers n'appliquent pas la dose recommandée par le fabricant des pesticides indique que ceux-ci, quel que soit leur niveau d'études, ne lisent généralement pas la notice qui accompagne les pesticides et n'ont donc pas une bonne connaissance des pesticides. Ceci est également soutenu par le fait que certains maraîchers enquêtés $(9 \%$ ) appliquent à la fois deux produits à base de la même matière active, et $95 \%$ d'entre eux attestent n'avoir pas suivi une formation sur l'usage des pesticides (Tableau 5). De même les maraîchers ayant fait la formation agricole diplômante ne diffèrent des autres quant au dosage des pesticides (Tableau 4). N'ayant pas suivi une formation sur l'usage des pesticides et l'habitude de lire la notice des pesticides, la plupart de maraîchers a été plutôt initiée par leurs proches. $\mathrm{Ce}$ mode d'apprentissage ne peut que répercuter les erreurs des uns sur les autres. La plupart des maraîchers mélangent 2 ou plusieurs pesticides dans un réservoir sans connaitre au préalable leurs comptabilités et les appliquent à la fois au moyen d'un pulvérisateur. Assogba-Komlan et al. (2007) au Bénin, Ghorbel et al. (2016) en Tunisie et Lwin et al. (2017) en Birmanie (Myanmar) ont rapporté des résultats similaires. Très souvent des engrais liquides (par ex. D.I. grow green, D.I. grow red) sont ajoutés à la solution des pesticides. Si la synergie de certains pesticides peut être bénéfique (accroissement de l'efficacité), elle peut toutefois avoir des effets négatifs en cas des produits incompatibles. Pour Banko Plus (Chlorothalonil 550g/L + Carbendazim $100 \mathrm{~g} / \mathrm{L})$, par exemple, le fabricant déconseille le mélange avec les engrais liquides. Notons que les maraîchers enquêtés utilisaient jusqu'à 9 pesticides au cours d'un cycle végétatif. Ce nombre élevé des pesticides serait lié au fait que les ennemis de culture auraient développé une résistance aux premiers pesticides appliqués, et dans ce cas l'utilisation d'un nouveau groupe des pesticides s'avère nécessaire. Un mélange des pesticides signifie un mélange de 2 ou plusieurs molécules actives. La synergie accroit également le risque d'intoxication pour le producteur qui s'expose en une fois à 2 ou plusieurs molécules actives. Pourtant seul le $1 / 5$ d'enquêtés ont reconnu que l'utilisation des pesticides pourraient les exposer à l'intoxication (Tableau 6). Ceci traduit ainsi l'ignorance du danger encouru et la modicité d'équipements de protection utilisés par la majorité de maraîchers. Onil \& Louis (2001) ont rapporté trois voies d'exposition aux pesticides : cutanée, respiratoire et orale. Dans une étude simulant le risque d'exposition cutanée des maraîchers opérant sans tenue de protection appropriée (mains et avant-bras non gantés) à 3 pesticides (acétaminipride, primicarbe et Chlorpyrifosmethyl), in vitro, à travers la peau de l'oreille porcine ; Beránková et al. (2017) ont rapporté des valeurs inquiétantes de risque d'exposition des maraîchers aux primicarbe et Chlorpyrifos-methyl traduisant ainsi un risque pour la santé des maraîchers. Compte tenu du grand nombre des pesticides utilisés et la fréquence d'application (risque très grand de bioaccumulation des pesticides), les maraîchers de Nkolo et ses environs qui ne portent pas de tenue de protection appropriée pendant le traitement (Photo 2) encourent un grand risque d'intoxication chronique aux pesticides. Les emballages des pesticides sont généralement abandonnés au champ ou incinérés comme initialement observé dans d'autres pays africains (Ahouangninou, 2013; Kanda, 2013). L'abandon des emballages au champ constitue un grand danger pour les enfants et les non-initiés qui peuvent s'en servir comme emballages et récipients de second usage. L'incinération des emballages (déchets des pesticides et matériels contaminés y compris) n'est pas non plus une bonne pratique car pendant la combustion, certains pesticides produisent des fumées hautement toxiques dont l'inhalation et/ou le contact sont nocif s pour l'homme et les animaux (Congo, 2013). De même, l'auteur souligne que l'enfouissement des emballages (pratiqué par $6 \%$ d'enquêtés dans cette étude), des reliquats et déchets de pesticides présente le risque de contamination des nappes souterraines. A Nkolo et ses environs, les champs maraîchers étant majoritairement installés le long de cours d'eau pour des facilités d'arrosage, une partie d'emballages abandonnés au champ finit dans le cours d'eau emportés par des vents violents ou des eaux de ruissellement. II en est de même pour des pesticides accumulés dans sol qui, après des fortes pluies, sont charriés dans les eaux du ruissellement vers les cours d'eau et des particules volatiles pendant le traitement dont certaines se déposent directement dans les cours d'eau. A la fin du traitement, les maraîchers se lavent et lavent leurs vêtements dans les cours d'eau. La contamination des cours d'eau aux pesticides n'est donc pas exclue dans la zone d'études quand bien même la plupart des maraîchers affirment entretenir les pulvérisateurs au champ pour ne pas polluer les cours d'eau (Tableau 5). Par ailleurs, il est important de noter que si tous les états devraient appliquer scrupuleusement les dispositions du Code de conduite international pour la distribution et l'utilisation des pesticides de la FAO, à savoir que « les fabricants et distributeurs des pesticides doivent fournir en même temps que les produits, les services et facilités permettant aux utilisateurs de se débarrasser en sécurité des récipients vides et des 
déchets de pesticides » (FAO/OMS, 2002 cité par Congo, 2013), le risque d'intoxication liée à la gestion des emballages serait nul ou minime. A l'instar de l'étude menée au Togo (Kanda et al., 2013), la durée avant la récolte (DAR) observée est différemment appréciée par les maraîchers et ne dépend pas du produit (voir notice sur l'emballage) comme le recommande la bonne pratique. La DAR appliquée par $52 \%$ d'enquêtés est de 7 jours, cette durée est au regard des DAR recommandées (Tableau 3), assez suffisante pour éliminer les résidus de la plupart des pesticides utilisés. Toutefois, dans la mesure où les pesticides sont généralement mélangés dans la zone d'études, la DAR idéale serait celle du pesticide à durée la plus longue, soit au moins 15 jours (exception faite du Ridomil) pour notre cas. Cette DAR est cependant pratiquée par $10 \%$ seulement d'enquêtés. Si les maraîchers (producteurs) mal protégés pendant le traitement sont directement exposés à l'intoxication aux pesticides lors du traitement, ils le sont également, indirectement comme tous les consommateurs des légumes lorsque la DAR n'est pas respectée. Les résultats montrent que $20 \%$ d'enquêtés doutent de la qualité des récoltes des autres maraîchers prétextant qu'ils ne respectent pas la DAR (Figure 5.b). Dans certains cas (vol des légumes, spéculation des prix sur les marchés urbains), certains enquêtés soutiennent que la récolte des légumes est faite avant la DAR requise. II s'avère ainsi donc impérieux de contrôler la qualité des récoltes en dosant la teneur en résidus des pesticides en vue d'évaluer le risque potentiel auquel serait exposé les consommateurs des légumes produits à Nkolo et ses environs. Plusieurs études ont rapporté des cas d'intoxication aux pesticides (Congo 2013). Contrairement à la $\mathrm{RD}$ Congo, des cas documentés dans quelques pays africains ont été rapportés, notamment au Maroc (2609 cas en 2009), au Bénin (105 cas, dont 8 décès en 2008), au Mali (329 cas, avec 30 à 210 décès et 1150 à 1980 intoxications chroniques en 2000) et au Burkina Faso (7 cas dans la région de la boucle du Mouhoun en 1996). II ressort donc, que les pesticides sont une arme à double tranchant, autant ils ont une utilité incontestable, autant ils peuvent engendrer des conséquences désastreuses pour la santé humaine, animale et l'environnement si les conditions de formulation, de transport, de stockage et d'utilisation ne sont pas respectées (Congo, 2013; Ghorbel et al., 2016). Compte tenu de la fréquence des légumes dans les repas quotidiens et de leur importance prouvée pour la santé humaine ("Pour être en bonne santé, manger cinq légumes et fruits par jour'), la réglementation de l'utilisation des pesticides s'impose pour éviter le problème de santé publique et de pollution de l'environnement. En RD Congo, le secteur des pesticides est régi par deux textes législatifs de base : la Loi $n^{\circ}$ 11/022 du 24 décembre 2011 portant Principes fondamentaux relatifs à l'agriculture et le Décret $n^{\circ}$ 05/162 du 18 novembre 2005 portant Réglementation phytosanitaire. Toutefois, comme pour la Tunisie (Ghorbel et al. 2016), ces textes fixent généralement les modalités et les conditions d'obtention de l'homologation et de l'autorisation de vente des pesticides. Pour la RD Congo, Mamba-Mamba (2015), note que la mise en œuvre de la législation des pesticides, notamment en ce qui concerne leur gestion, n'est pas encore efficiente du fait de sa faible diffusion, de sa non-vulgarisation et du manque de textes d'application. Au-delà des importateurs (obligation réglementaire: homologation, autorisation d'importation) et des distributeurs (obligation réglementaire: autorisation d'ouverture d'officine de vente des pesticides), le devenir des pesticides n'est pas maîtrisé auprès des revendeurs et maraîchers (utilisateurs agricoles) sur qui ne pèse aucune exigence spécifique de la part du ministère ayant en charge la gestion des pesticides. La plupart de maraîchers enquêtés $(72 \%)$ s'approvisionnaient localement mais aucun des détenteurs d'officines de vente des pesticides n'a une formation experte sur les pesticides pour les encadrer. Ainsi, en plus d'un besoin urgent de formation et de sensibilisation permanente des maraîchers, les textes législatifs en vigueur doivent être assortis des contraintes incitatives à une utilisation rationnelle des pesticides, notamment par : i) l'inspection des champs maraîchers par le service de contrôle du Ministère de l'Agriculture, Pêche et Élevage pour s'assurer de l'application appropriée des pesticides et des conditions de protection requises pour les maraîchers, ii) le contrôle des résidus des pesticides dans les récoltes et la destruction des récoltes impropres avec sanctions, iii) la formation des détenteurs des officines de vente des pesticides pour une expertise sur les pesticides et la gestion des emballages des pesticides. Enfin, en vue de réduire l'incidence négative des pesticides chimiques de synthèse, l'utilisation des biopesticides, produits relativement moins toxiques et respectueux de l'environnement peut être une alternative adéquate. Des résultats intéressants des biopesticides ont été rapportés dans plusieurs régions maraichères du monde (Deravel et al., 2014 ; Mondedji et al., 2015 ; Bhagwan et Kumar, 2017 ; Patel et Kumar, 2017). Pour la zone d'études, beaucoup d'efforts devraient être cependant fournis dans la mesure où seul un maraîcher sur les 46 enquêtés aurait à ce jour testé un biopesticide. 


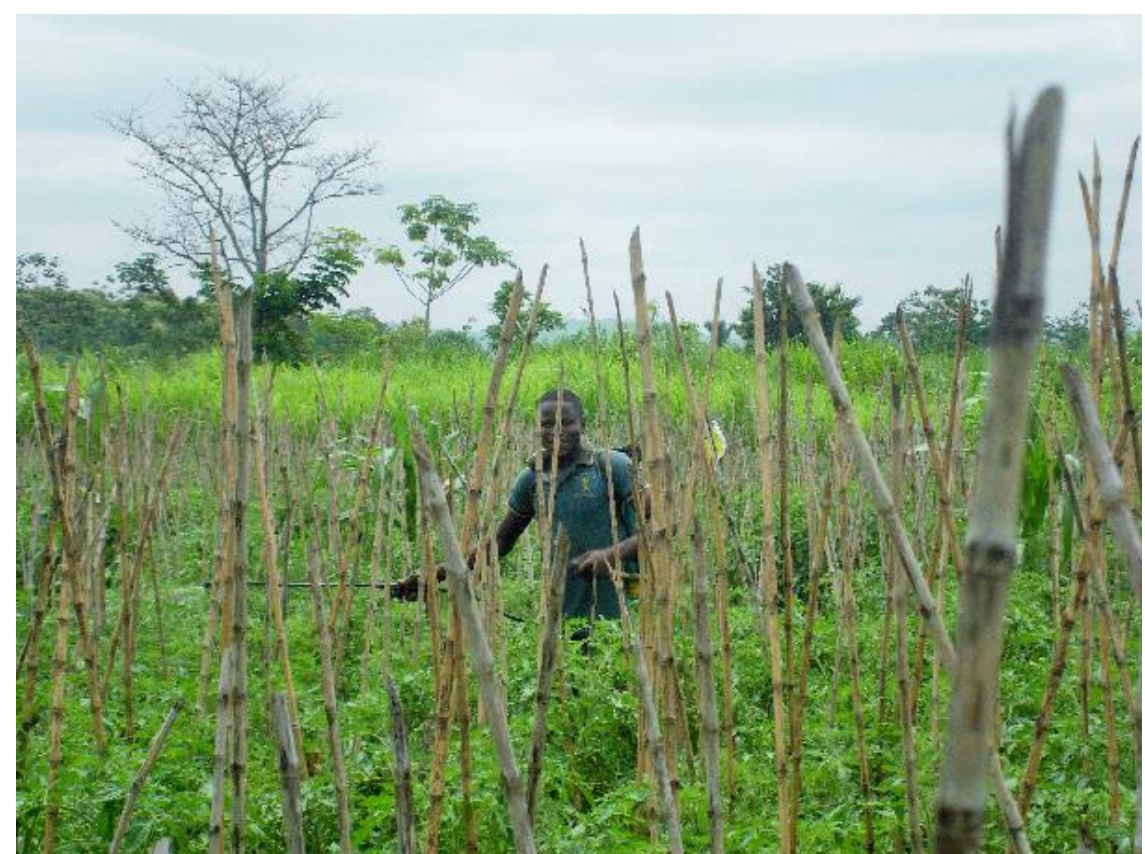

Photo 2 : Un maraîcher de tomate, sans vêtement approprié (T-shirt + culotte jeans et babouches aux pieds), en plein traitement phytosanitaire.

\section{CONCLUSION}

L'objectif de cette étude était d'évaluer les connaissances et les pratiques des maraîchers de Nkolo et ses environs quant à l'utilisation des pesticides. Tous les maraîchers enquêtés (100\%) ont affirmé que les pesticides sont nécessaires pour assurer de bons rendements des légumes fruits à Nkolo et ses environs. Ils appliquent systématiquement les pesticides dont les fongicides, insecticides et insecticide-acaricide, généralement à 7 jours et 14 jours d'intervalle respectivement pendant la saison sèche et la saison des pluies. Suivant le maraîcher, 1 à 9 pesticides sont utilisés par cycle de culture. Cependant, les maraîchers n'ont pas une bonne connaissance des pesticides et ne respectent généralement pas les recommandations des fabricants, notamment la dose à appliquer, le port d'une tenue de protection et la gestion des emballages. Ces résultats révèlent le risque potentiel d'intoxication aux pesticides qu'encourent les maraîchers et les consommateurs de légumes d'une part et d'autre part, l'urgente nécessité de former les maraîchers de Nkolo et ses environs sur l'utilisation judicieuse des pesticides chimiques de synthèse. Les études ultérieures devraient être focalisées notamment sur le contrôle de résidus des pesticides dans les récoltes. Les biopesticides qui ont déjà fait preuve d'efficacité avérée dans plusieurs régions du monde et qui sont moins toxiques pour l'homme et respectueux de l'environnement nécessitent d'être testés dans la zone d'étude. La mise au point des variétés résistances (par ex. croisement des variétés locales et les variétés allochtones) serait également une piste intéressante pour réduire l'utilisation des pesticides.

\section{REMERCIEMENTS}

Nous remercions le Programme d'Approvisionnement en Eau pour les Villages (PAEV-CBCo) pour l'appui logistique pendant l'enquête. 


\section{REFERENCES BIBLIOGRAPHIQUES}

Ahouangninou CA, 2013. Durabilité de la production maraîchère au Sud-Bénin : un essai de l'approche écosystémique. Thèse de doctorat, Université d'Abomey-Calavi, Benin.

Assogba-Komlan F, Anihouvi P, Achigan E, Sikirou R, Boko A, Adje C, Ahle V, Vodouhe R, Assa A, 2007. Pratiques culturales et teneurs en éléments anti nutritionnels (nitrates et pesticides) du Solanum macrocarpum au Sud du Bénin. African Journal of Food, agriculture, nutrition and development 7 (4): 1-21.

Beránková M., Hojerová J., Melegová, 2017. Exposure of amateur gardeners to pesticides via non-gloved skin per day. Food and Chemical toxicology 108 (A): 224-235.

Bhagwan DS. and Kumar A, 2017. Field efficacy of cypermethrin and certain biopesticides against brinjal shoot and fruit borer, (Leucinodes orbonalis Guenee) on Brinjal (Solanum melongena L.). Journal of Pharmacognosy and Phytochemistry 6 (4): 1930-1933.

Boroto $\mathrm{R}, 2014$. Water in urban and peri-urban horticulture in Democratic Republic of Congo. Nature and Faune Journal 28 (2): 67-70.

Congo AK, 2013. Risques sanitaires associés à l'utilisation de pesticides autour de petites retenues : cas du barrage de Loumbila. Thèse de Master, Ingénierie de l'eau et de l'environnement, Institut International d'Ingénierie, Ouagadougou, Burkina Faso. 57p.

Deravel J, Krier F, Jacques P, 2014. Les biopesticides, compléments et alternatives aux produits phytosanitaires chimiques (synthèse bibliographique). Base 18 (2) : 220-232.

Deviller J, Farret R, Girardin P, Rivière JL, Soulas G, 2005. Indicateurs pour évaluer les risques liés à I'utilisation des pesticides. Lavoisier (Editeur), Paris, France. 278 pp.

Ghorbel A, Lazreg Aref H, Darouiche MH, Nouri NM, Masmoudi ML, Akrout FM, 2016. Estimation du niveau de connaissance et Analyse toxicologique chez des manipulateurs de pesticides organophosphorés exposés au Fénitrothion dans la région de Sfax, en Tunisie. International Journal of Innovation and Scientific Research 25(1): 199-211.

Kanda M, Boundjou GD, Wala K, Gnandi K, Batawila K, Sanni A, Akpagana K, 2013. Application des pesticides en agriculture maraîchère au Togo. VertigO. La revue électronique en sciences de l'environnement 13

www.vertigo.revues.org/13456.

Lwin TZ, Min AZ, Robson MG, Siriwong W, 2017. Awareness of safety measures on pesticide use among farm workers in selected villages of Aunglan Township, Magway Division, Myanmar. Journal of Health Research 31 (5): 403-409.

Mamba Mamba D, 2015. Gestion des pesticides en RD Congo. Ministère de l'Agriculture, Pêche et Élevage. www.au-ibar.org.

Mawussi G, Kolani L, Devault DA, Koffi-Kouma AA, Sanda K, 2015. Utilisation de pesticides chimiques dans les systèmes de production maraîchers en Afrique de l'Ouest et conséquences sur les sols et la ressource en eau : Le cas du Togo. 44è congrès du Groupe Français des Pesticides, 26-29 mai 2014, Actes du colloque, Schoelcher, France, pp46-53.

Mfuti DK, Menakuntuala BH, Bambala EN, Longi KH, Kupesa BT, Lema KA, 2016. Identification et occurrence des fourmis dans les champs de manioc au centre de recherche de Mvuazi. Afrique Science 12 (6) : 383-390.

Mondedji AD, Nyamador WS, Amevoin K, Adéoti R, Abbévi GA, Koffivi ketoh G, Glitho IA, 2015. Analyse de quelques aspects du système de production légumière et perception des producteurs de l'utilisation d'extraits botaniques dans la gestion des insectes ravageurs des cultures maraîchères au Sud du Togo. International Journal of Biology and Chemistry Sciences 9(1): 98-107.

Muliele MT, Nsombo MB, Kapalay MO, Mafuka MP, 2017. Amendements organiques et dynamique de l'azote minéral dans le sol sableux de Kinshasa (RD Congo). Journal of Animal and Plant Sciences 32 (2): 5156-5167.

Muzingu NB, 2010. Les sites maraîchers coopérativisés de Kinshasa en RD Congo. Contraintes environnementales et stratégies des acteurs. Thèse de doctorat, Université catholique de Louvain, Belgique.

Onil S. et Louis S, 2001. Guide de prévention pour les utilisateurs des pesticides en cultures maraîchères. Guide technique. Études et Recherches. Institut de recherche en santé et en sécurité du travail (IRSST) du Québec, Canada. 92p.

Patel VD. and Kumar A, 2017. Field efficacy of certain botanical and chemical insecticides against chilli 
thrips [Scirtothrips dorsalis (Hood)] on Chilli (Capsicum annuum L.). Journal of Pharmacognosy and Phytochemistry 6(4): 497499.

Sougnabe SP, Yandia A, Acheleke J, Brevault T, Vaissayre M, Ngartoubam LT, 2010. Pratiques phytosanitaires paysannes dans les savanes d'Afrique centrale. In Seiny-Boukar L. et Boumard P. Savanes africaines en développement : innover pour durer, 20-23 Avril 2009, Actes du colloque, Garoua, Cameroun, pp. 1-13.
Tachin ES, 2011. Protection des végétaux et gestion des cultures maraichères: les pesticides chimiques, à la fois utiles et dangereux. https://lanouvelletribune.info/archives/sante/731 5-protection-des-vegetaux-et-gestion-descultures-maraicheres.

Wade CS, 2003. L'utilisation des pesticides dans l'agriculture périurbaine et son impact sur l'environnement. Thèse de doctorat, Université Cheick Anta Diop, Dakar, Sénégal. 